\title{
Adding motivational interviewing and thought mapping to cognitive-behavioral group therapy: results from a randomized clinical trial
}

\section{Adicionando a entrevista motivacional e o mapeamento cognitivo à terapia cognitivo-comportamental em grupo: resultados de um ensaio clínico randomizado}

\author{
Elisabeth Meyer, ${ }^{1}$ Roseli G. Shavitt, ${ }^{2}$ Carl Leukefeld, ${ }^{3}$ Elizeth Heldt, ${ }^{1}$ Fernanda P. Souza, ${ }^{1}$ Paulo Knapp, ${ }^{1}$ \\ Aristides V. Cordioli ${ }^{1}$ \\ ${ }^{1}$ Anxiety Disorders Program, Department of Psychiatry, Universidade Federal do Rio Grande do Sul (UFRGS), Porto Alegre (RS), Brazil \\ ${ }^{2}$ Obsessive-Compulsive Spectrum Disorders Program, Department and Institute of Psychiatry, Hospital das Clínicas, School of Medicine, \\ Universidade de São Paulo (USP), São Paulo (SP), Brazil \\ ${ }^{3}$ Center on Drug and Alcohol Research, University of Kentucky, Lexington, Kentucky, USA
}

\begin{abstract}
Objective: Recent factor-analytic studies of obsessive-compulsive disorder identified consistent symptom dimensions. This study was designed in order to observe which obsessive compulsive symptom dimensions could be changed by adding two individual sessions of motivational interviewing and thought mapping of cognitive-behavioral group therapy using a randomized clinical trial. Method: Forty outpatients with a primary diagnosis of obsessive-compulsive disorder were randomly assigned to receive cognitive-behavioral group therapy (control group) or motivational interviewing+thought mapping plus cognitive-behavioral group therapy. To evaluate changes in symptom dimensions, the Dimensional Yale-Brown Obsessive-Compulsive Scale was administered at baseline and after treatment. Results: At post-treatment, there were statistically significant differences between cognitive-behavioral group therapy and motivational interviewing+thought mapping+cognitivebehavioral group therapy groups in the mean total Dimensional YaleBrown Obsessive-Compulsive Scale score, and in the contamination and aggression dimension score. Hoarding showed a statistical trend towards improvement. Conclusion: These findings suggest that adding motivational interviewing+thought mapping to cognitive-behavioral group therapy can facilitate changes and bring about a decrease in the scores in different obsessive-compulsive disorder symptom dimensions, as measured by the Dimensional Yale-Brown Obsessive-Compulsive Scale. Nonetheless, additional trials are needed to confirm these results.
\end{abstract}

Descriptors: Signs and symptoms; Obsessive-compulsive disorder; Cognitive therapy; Behavior therapy; Interview, psychological

\begin{abstract}
Resumo
Objetivo: Recentes estudos utilizando análise fatorial no transtorno obsessivocompulsivo identificaram dimensöes consistentes dos sintomas. Este estudo foi delineado para observar quais dimensôes dos sintomas obsessivo-compulsivos podem ser modificadas adicionando duas sessöes individuais de entrevista motivacional e mapeamento cognitivo à terapia cognitivo-comportamental em grupo usando um ensaio clínico randomizado. Método: Quarenta pacientes ambulatoriais com diagnóstico primário de transtorno obsessivo-compulsivo foram alocados aleatoriamente para receber terapia cognitivo-comportamental em grupo (grupo controle) ou entrevista motivacional+mapeamento cognitivo+terapia cognitivo-comportamental em grupo. Para avaliar mudanças nas dimensōes dos sintomas, foi administrada a Escala Dimensional para Sintomas Obsessivo-Compulsivos de Yale-Brown antes do início e após o tratamento. Resultados: Ao final do tratamento houve diferença estatisticamente significativa entre a terapia cognitivo-comportamental em grupo e entrevista motivacional+mapeamento cognitivo+terapia cognitivocomportamental em grupo na média do escore total da Escala Dimensional para Sintomas Obsessivo-Compulsivos de Yale-Brown e no escore da dimensão de contaminação e agressão. Colecionismo apresentou melhora com tendência estatística. Conclusão: Esses achados sugerem que acrescentar entrevista motivacional+mapeamento cognitivo à terapia cognitivo-comportamental em grupo pode facilitar mudanças na redução dos escores nas diferentes dimensóes dos sintomas, como indicado pela Escala Dimensional para Sintomas Obsessivo-Compulsivos de Yale-Brown. No entanto, são necessários estudos adicionais para confirmar estes resultados.
\end{abstract}

Descritores: Sinais e sintomas; Transtorno obsessivo-compulsivo; Terapia cognitiva; Terapia comportamental; Entrevista psicológica
Submitted: January 29, 2009

Accepted: September 14, 2009
Correspondence

Elisabeth Meyer

Department of Psychiatry, Universidade Federal do Rio Grande do Sul R. Ramiro Barcelos, 2350, Room 400N

90035-903 Porto Alegre, RS, Brazil

Phone: (+55 51) 3328-2174

E-mail: meyer-beth@hotmail.com 


\section{Introduction}

Obsessive-compulsive disorder (OCD) is a chronic disease characterized by intrusive thoughts and rituals performed to relieve the anxiety or discomfort, although the result is probably an increase in distress over time. Several studies have reported the importance of groups of symptoms in specific dimensions, assuming that patients may present symptoms in one or more dimensions, with varying degrees of severity among them. ${ }^{1-3}$ These proposed dimensions are: 1) aggressive obsessions and related compulsions (e.g., checking that nothing terrible has happened); 2) sexual and religious obsessions and related compulsions (e.g., excessive concern with what is morally right or wrong); 3) symmetry, ordering, counting, and arranging obsessions and compulsions (e.g., being afraid of not saying "just the right thing"); 4) contamination obsessions and cleaning compulsions (e.g., repeated cleaning of household items or other inanimate objects); 5) hoarding and collecting obsessions and compulsions (e.g. being unable to decide to throw things away), and 6) miscellaneous (e.g. ascribing special significance to colors). Researchers ${ }^{4,5}$ have suggested that the dimensional approach might help guide research on the treatment of OCD, including the development of Cognitive Behavioral Therapy (CBT) techniques tailored to specific symptom dimensions, which could improve response rates. ${ }^{6,7}$ Based on earlier studies using factor analysis to group patients with certain obsessive-compulsive (OC) symptoms, Rosario-Campos et al. ${ }^{2}$ developed the Dimensional Yale-Brown Obsessive-Compulsive Scale (DY-BOCS).

Although CBT has been shown to be effective for OCD, ${ }^{8,9}$ changing ritual behavior can be difficult and anxiety-provoking. When OCD patients see possible benefits in stopping the rituals, they tend to feel ambivalent towards changing behavior. Motivational Interviewing (MI) is an effective strategy for helping individuals increase their motivation or readiness to change. MI helps the therapist and patient to achieve a common understanding about the patient's awareness of change, facilitating the movement through decisional analysis and behavioral change. ${ }^{10,11}$ Miller and Rollnick have described five strategies of MI: 1) express empathy and acceptance (i.e., empathy means acceptance and understanding another's perspective and feelings neutrally, without judging or evaluating in any way); 2) develop discrepancy (i.e., perceive differences between a current situation and hope for the future); 3) avoid argumentation (i.e., when the patient refuses to complete a task, it is time to stop forcing the point and to modify the strategy); 4) roll with resistance (i.e., arguing for change with a patient will likely trigger the patient to argue against it), and 5) support self-efficacy (i.e., a person's belief in his or her ability to carry out a specific behavior). ${ }^{11} \mathrm{MI}$ can be utilized as independent, stand-alone intervention or can be integrated with other treatment modalities. Resisting the righting reflex (the "righting reflex" refers to our natural urge as human beings to put things right: e.g. health care providers are probably more inclined to have a righting reflex ${ }^{12}$ ), understanding and exploring the patient's own motivations, empowering the patient, encouraging hope and optimism, all help a therapist promote collaboration and reduce resistance. ${ }^{12}$ The techniques of MI are described in detail in Miller and Rollnick, ${ }^{11}$ and Rollnick, Miller and Butler. ${ }^{12}$

Eventually, the inability to concentrate creates difficulties for OCD patients in focusing their attention. Some OCD patients cannot make the connection between a person's behavior in the context of their environment, thoughts, and feelings and how some experiences are related to desirable outcomes, while others are related to undesirable ones. Thought Mapping (TM) ${ }^{13,14}$ was developed based on the Transtheoretical Model ${ }^{15}$ and the first four stages of change. It is a visual technique that uses a predesigned map and is very useful in keeping individual discussions on track. Because the aspects worked on during the session can be visualized, TM might be particularly helpful for patients who are engaged in mental ritual activity and/or have been presenting excessive uncertainty or doubt about what was said, during the consultation with the mental health professional. The use of visual aids (paper and pen) in TM may help the patient focus on the intervention. A personal "thought map", for OCD-related dysfunctional thoughts and behaviors is developed by each patient to organize his or her own personal thoughts and behaviors. In doing this, patients can express parallel ideas, complex and distant thoughts, and connections between behaviour and feelings. It can also help patients identify more clearly where changes need to take place, to explore behavioral choices and subsequent results, and to consider solutions to the presenting problem. The TM technique is described in detail in Leukefeld et al. ${ }^{16}$

The overall purpose of the present study was to examine if adding two individual sessions of MI+TM before starting 12 weeks of CBGT in an adult OCD outpatient treatment program would facilitate changes in the OC symptom dimensions when compared with CBGT alone, as measured by a structured interview, in a randomized clinical trial.

\section{Method \\ 1. Participants}

Sixty-five adult outpatients meeting DSM-IV criteria for OCD, as determined by the Brazilian version ${ }^{17}$ of Structured Clinical Interviews (SCID) ${ }^{18}$ for DSM-IV attending an Anxiety Disorders Program (PROTAN) in Porto Alegre, Brazil, were assessed from January 2007 to December 2007 (see Figure 1). Participants were recruited among the general population by means of lectures, radio and TV interviews, and newspaper advertisements that offered CBGT to patients with OCD. Interviews were conducted by trained psychiatrists or clinical psychologists, experienced in treating OCD patients. Inclusion criteria based on assessment included: 1) age between 18 and 65 years old; 2) having OCD as the most significant current psychiatric diagnosis; 3) Yale-Brown Obsessive-Compulsive Scale (Y-BOCS) total score > 16; and 4) no change in anti-obsessive medication (if applicable) for at least three months prior to study entry. Consistent with our previous researches, ${ }^{19-21}$ individuals were excluded from the current study if they had an additional diagnosis of another anxiety or mood 


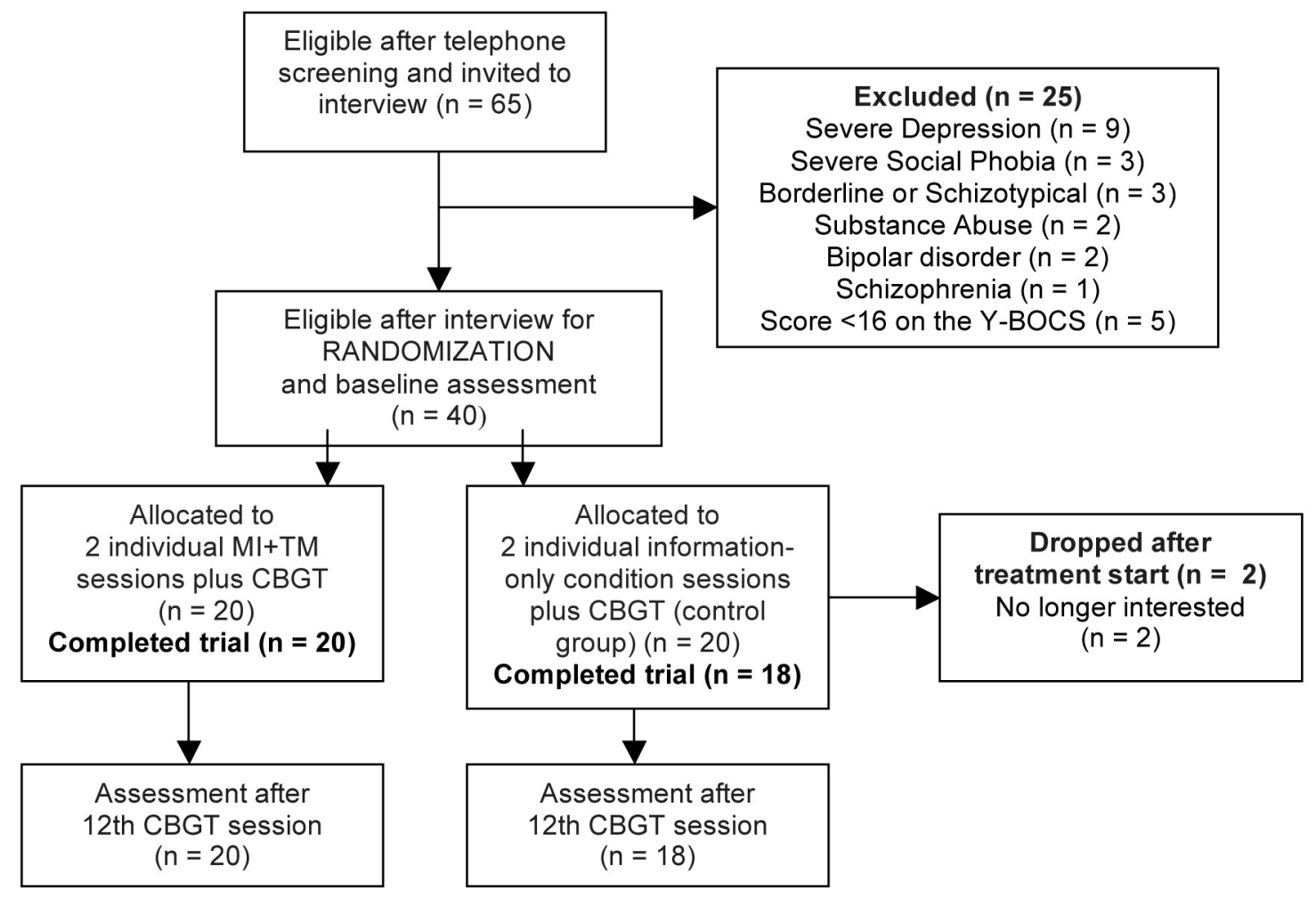

Figure 1 - Flowchart of a Randomized Clinical Trial comparing MI+TM plus CBGT and information-only condition plus CBGT in the treatment of patients with Obsessive- compulsive disorder

disorder of equal or greater severity than their OCD, significant suicidality, present alcohol or substance abuse or dependence, or severe psychiatric disorder (schizophrenia and other psychotic disorders). Twenty-five patients were determined not eligible. The reasons for exclusion were: Severe Depression $(n=9)$, severe social phobia $(n=3)$, personality disorders: borderline or schizotypical $(n=3)$, substance abuse $(n=2)$, bipolar disorder $(n=2)$, schizophrenia $(n=1)$, or a score $<16$ on the Y-BOCS $(\mathrm{n}=5)$. After signing an informed consent form, 40 selected patients were randomized: 20 patients $(50 \%)$ to $\mathrm{MI}+\mathrm{TM}+\mathrm{CBGT}$ group and 20 patients (50\%) to the control group. Of the 40 outpatients who composed the sample, 38 completed the study. Two patients (5\%) dropped out of the control group after the third session (they contacted the therapist to state that they would no longer attend the sessions).

\section{Study design and procedures}

Randomization of the MI+TM+CBGT group or the control group was performed using a research randomizer (see: www. randomizer.org/index.htm). The study was conducted in three successive periods of 12 weeks, with one MI+TM+CBGT and one parallel information-only condition plus CBGT (control group). Participants in both the MI+TM and control groups received the CBGT as usual; they differed only in the style of individual sessions received prior to CBGT. The individual interventions were carried out by a doctoral-level therapist, who did not participate in the CBGT sessions. CBGT had six to eight patients, and sessions were conducted by the same therapist, assisted by a co-therapist, both masters-level student psychologists with prior CBGT experience, who were blinded to the individual interventions. Patients were also instructed not to reveal the content of their individual sessions. The CBGT was conducted in a closed-ended group during the course of 12 weekly two-hour sessions, carried out once a week, over three months. The treatment approach integrated psychoeducation, techniques of Exposure and Response Prevention (ERP), cognitive techniques to modify dysfunctional thoughts and beliefs, strategies to prevent relapses, homework ERP and cognitive exercises for each session, and group techniques.

The Hospital de Clínicas of Porto Alegre review board approved the study (Process:06/171). Written informed consent was obtained from all participants, after a description of the study, emphasizing that they would be randomized into one of two treatment conditions: 1) two individual sessions of $\mathrm{MI}+\mathrm{TM}+\mathrm{CBGT}$, or 2) two information-only condition sessions plus CBGT (the control). Each participant was assured that their decision to participate or not participate in the study would not interfere with their access to treatment.

\section{Treatment}

1) Cognitive behavioral group therapy (CBGT)

The CBGT was conducted in a closed-ended group during the course of 12 weekly two-hour sessions, based on a structured manualbased approach developed by one of the authors (AVC), and has been used in other trials. ${ }^{19-21}$ The treatment started with a presentation 
of OCD symptoms, the rationale of ERP therapy and treatment targets, followed by demonstrations and practical ERP exercises. In the subsequent sessions, commonly held dysfunctional beliefs about OCD were explained and cognitive techniques for their correction were given, followed by practical exercises in ERP and cognitive restructuring. At the end of each session, homework was given to each patient. ${ }^{19,22}$ The manual is described in detail elsewhere. ${ }^{22}$

2) Motivational Interviewing (MI) + Thought Mapping (TM) plus CBGT group

The MI+TM approach consisted of two 60-minute individual weekly sessions before the patients started the 12 CBGT sessions. The interventions were carried out by a doctoral-level therapist, who did not participate in the CBGT sessions. The two sessions are designed to allow the patient to discover what he or she can expect from the treatment, as well as increasing the motivation for change in a collaborative process involving the therapist and patient. No manual was given, allowing the therapist autonomy to follow the patient using MI strategies. The sessions were patient-centered, used open-ended and non-confrontational questions, to encourage patients to talk about why, how and when they might change, reinforcing the idea that the focus of behavior change resides in the patient, not in the therapist. A key goal in MI is to increase the importance of change from the patient's perspective. In CBT, the therapist takes the role of an advocate for change, to at least some degree, but in MI, the therapist does not argue in favor of change, but helps the patient to become a more effective advocate for their own change. ${ }^{23}$ Rollnick ${ }^{12}$ points out that if the patient is placed center stage, and guided through a conversation about why and how to change, outcomes will be improved. The two individual sessions were structured as: 1) identifying and exploring reasons for change; 2) helping the patient to acknowledge and discuss their mixed feelings about possible benefits in stopping the rituals, thereby tipping the balance in favor of change (e.g., "How do you think your life might be different, both positively, and negatively, if you were to stop the rituals?"); 3) using reflective listening when trying to express patient understanding (e.g., "So you're saying that you want to stop all the rituals, but, at the same time, you're worried whether you can deal with the anxiety during the therapy exercises"); 4) inviting the patient to define goals (e.g. invite the person to describe perceived barriers/concerns changing); 5) reflecting and summarizing concerns raised by the patient during the decision-making process; 6) choosing personal strategies (e.g., "If you decided to change how would you do it?"). The purpose of this intervention model was that of exploring and resolving ambivalence in avoiding rituals, and to increase and renew patient motivation or readiness to adhere to the ERP exercises which are part of CBGT. It was also to help strengthen the patient's selfefficacy (e.g. identify existing skills and how to generalize those to the OCD context) and in addition, the therapist explained the CBGT model, explained ERP, and encouraged each patient to tolerate and manage anxiety provoked by ERP.

For this study, the therapist and the patient completed a map together and patients were encouraged to analyze their TM and to develop strategies to face the anxiety produced by their obsessions with alternative behavioral responses. TM is a structured and preformatted mapping approach to link nodes (visually represented as boxes) as feelings, thoughts, and actions in treatment sessions with links (visually represented by lines) to show relationships on paper between nodes. Utilizing TM allows the patient to see the role of thoughts/ beliefs/ feelings and behavior and the influences working among them all. The first part of the map (Figure 2) was used to facilitate problem recognition and identification (questions 1-3: ANTECEDENTS):

The second part (questions 4-6; Figure 3) was for problem solutions: CONSEQUENCES, as showed above:

3) Two-session individual information-only condition plus CBGT (control group)

In order to control the attention, duration and time spent in contact with the therapist treating the MI+TM condition, we created a comparison condition. The control condition was two 60-minute individual weekly sessions before the 12 sessions of CBGT and was administered by one doctoral-level therapist who did not participate in the group sessions. As an information-only condition, the therapist provided information about smoking cessation (session 1), and educational physical activity (session 2). Sessions were conducted in the style of a lecture and presented information such as: a) passive smoking exposure causes heart disease and lung cancer in non-smoking adults; b) exposure to nicotine and passive smoking is measured by testing the saliva, urine, or blood for the presence of a chemical called cotinine; c) most adults need at least 30 minutes of moderate physical activity at least five days per week; d) for all individuals, some activity is better than none. Regular exercise can prevent or delay diabetes and heart trouble. Participants could ask questions at any time. In the information-only condition, non-motivational interviewing components or TM were used, and presumably the intervention did not focus on enhancing commitment to change.

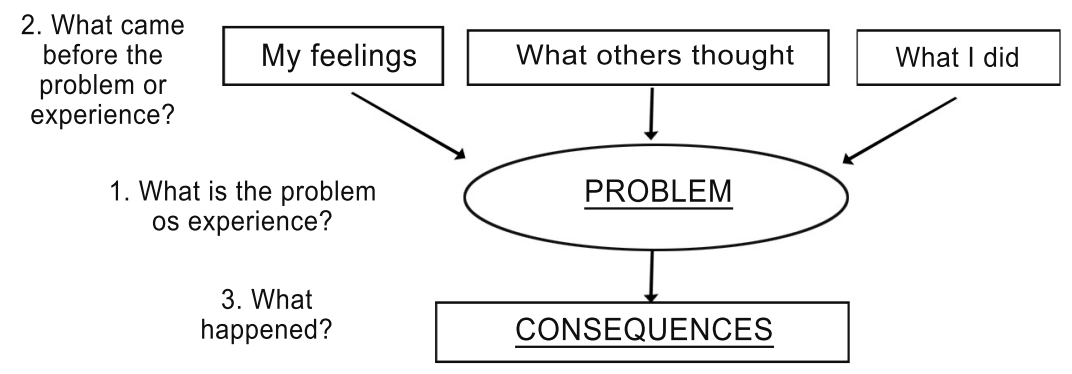

Figure 2 - First part of the map 


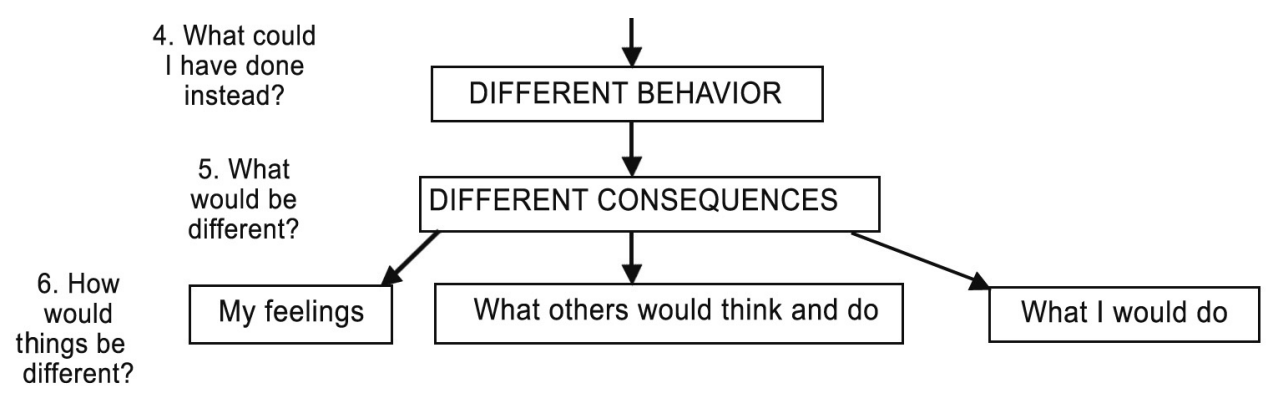

Figure 3 - Second part of the map

\section{Assessments}

Participants completed the following measures at baseline and post-treatment to evaluate outcome. The DY-BOCS ${ }^{2}$ includes a self-report section and an interviewer-administered section. The scale was simultaneously validated in Portuguese and English, and examines OC symptoms on six specific dimensions: 1) obsessions about harm due to aggression/injury/violence/natural disasters and related compulsions; 2) obsessions concerning sexual/moral/religious and related compulsions; 3 ) obsessions about symmetry/'just-right' perceptions, and compulsions to count or order/arrange; 4) contamination obsessions and cleaning compulsions; 5) obsessions and compulsions related to hoarding, and 6) miscellaneous obsessions and compulsions that relate to somatic concerns and superstitions, amongst other symptoms. This instrument measures the severity of each symptom dimension. For each dimension, there are three questions with a 0-5 point rating scale to measure time consumed by the symptoms, distress and interference (maximum score in each dimension $=15$ ). This interview assesses lifetime, current severity, and age at onset. Therefore, the baseline and post-treatment severity of each dimension were measured independently.

The Brazilian version ${ }^{24}$ of the Y-BOCS ${ }^{25}$ was used to assess severity of OCD symptoms, and included 10 questions: five for obsessions and five for compulsions, including time taken up by the symptoms, the level of interference in daily activities and distress, resistance and control of symptoms. Each item was scored from 0 to 4 with a maximum score of 40 .

The Clinical Global Impressions Scale - Severity subscore (CGI-S, adapted version ${ }^{26}$ investigates the health professional's impression of the severity of the patient's problem.

These instruments were administered by independent evaluators at baseline (before the two individual sessions) and after completing CBGT, by masters-level psychologists, trained on the application of the instruments, with experience in treating OCD patients, and blinded to group allocation. Every patient was reviewed at baseline and post-treatment by the same evaluator, in order to minimize the inter-rater variability.

Patients were also assessed with regard to their sociodemographic and clinical characteristics, including age, gender, years of education, marital status, use of anti-obsessional drugs, age at onset, age at which OCD symptoms started to interfere with daily activities, and the duration of the illness.

\section{Statistical analysis}

Shapiro-Wilk tests of the distribution of data were performed, as well as analysis to look for differences by type of condition (MI+TM+CBGT vs control group) across all key variables with t-tests, one-way ANOVA, Mann-Whitney test or Wilcoxon test for continuous variables, and Pearson $\chi^{2}$ test for nominal variables. We used non-parametric statistics whenever appropriate. The comparison of pre- and post-treatment scores was performed using t-test paired samples or with McNemar Chi-Square test. Analyses of covariance (ANCOVA) were used to control potential confounding variables. A positive response to treatment was defined as $35 \%$ or greater reduction in baseline Y-BOCS scores. Pearson $\chi^{2}$ test was used for dichotomic data: improved (reduction $\geq 35 \%$ on the Y-BOCS) versus non-improved (reduction $\leq 35 \%$ on the Y-BOCS). Patients who responded to treatment were also classified as having full remission for YBOCS scores $\leq 8$ and CGI $=1$ and partial remission when there was a reduction $\geq 35 \%$ on the Y-BOCS, but the total score on this scale was $>8$ and $\mathrm{CGI}=2$. To compare the changes in symptom dimensions from baseline to post-treatment, the results obtained from the two groups (MI+TM+CBGT and CBGT) were analyzed in two ways: 1) by comparing the DY-BOCS scores (reduction) by dimension, and 2) by noting the frequency (according to their presence or absence) of symptoms by dimension. The presence of a symptom dimension on the DY-BOCS was coded as 1 while its absence was coded as 0. DY-BOCS scores on six symptom dimensions were calculated by summing the scores from the sym ptom categories under each dimension. This score was used in all subsequent analyses. To verify which dimensions improve more and by how much, in both groups, a $\Delta$ specification of the change was applied to generate the data presented on Table 1 . The mean of the deltas represents the overall average of the individual deltas of each patient, which was calculated using the following equation: $\Delta$ mean $=$ (post-treatment value - pre-treatment value) $/$ (pre-treatment value). Rates were compared across the two groups with the Pearson $\chi^{2}$ test. The last-observation-carried-forward approach was adopted for continuous data. An intention-to-treat approach was used for patients who dropped out, labeled nonimproved. All p-values were two-tailed, the statistical significance was set at the 0.05 level and the confidence level was 95\%. Statistical assessments were performed by the Statistical Package for Social Sciences for Windows, version 13.0. 
Table 1 - Comparison of mean rate (\%) of improvement between the Ml+TM CBGT and the control groups

\begin{tabular}{|c|c|c|c|c|}
\hline & \multirow{2}{*}{$\frac{\text { MI+TM CBGT }}{\Delta_{\text {mean }}(\mathrm{SD})(\mathrm{n})}$} & \multicolumn{3}{|c|}{ Control group } \\
\hline & & $\Delta_{\text {mean }}(S D)(n)$ & statistics & $\mathrm{p}$ \\
\hline DY-BOCS global score & $69.0(20.2)(20)$ & $52.8(31.4)(20)$ & $t_{s}=1.94$ & 0.062 \\
\hline Aggression & $92.6(11.2)(13)$ & $49.8(31.4)(11)$ & $t_{s}=4.30$ & 0.001 \\
\hline Sexual/religious* & $100(22.2$ to 100$)(4)$ & $57.1(0$ to 100$)(3)$ & $\mathrm{U}_{\mathrm{MW}}=3.5$ & 0.400 \\
\hline Symmetry & $77.2(26.8)(17)$ & $58.6(39.1)(17)$ & $t_{s}=1.62$ & 0.116 \\
\hline Contamination & $91.9(14.7)(11)$ & $62.9(29.6)(12)$ & $t_{s}=2.93$ & 0.008 \\
\hline Hoarding* & $100(57.1$ to 100$)(11)$ & $66.1(-66.7$ to 100$)(12)$ & $\mathrm{U}_{\mathrm{MW}}=38.5$ & 0.091 \\
\hline Miscellaneous & $78.5(33.1)(17)$ & $65.3(38.0)(12)$ & $t_{s}=0.99$ & 0.331 \\
\hline Y-BOCS total score & $75.0(15.6)(20)$ & $61.4(32.2)(20)$ & $t_{s}=1.71$ & 0.099 \\
\hline Y-BOCS obsessions & $69.3(17.9)(20)$ & $61.5(32.0)(20)$ & $t_{s}=0.95$ & 0.350 \\
\hline Y-BOCS compulsions & $81.0(17.5)(20)$ & $61.3(33.6)(20)$ & $t_{s}=2.32$ & 0.028 \\
\hline CGI & $76.9(11.2)(20)$ & $64.5(27.1)(20)$ & $t_{s}=1.89$ & 0.070 \\
\hline
\end{tabular}

${ }^{*}$ Results are shown by median (minimum to maximum): YBOCS = Yale-Brown Obsessive-Compulsive Scale; DY-BOCS = Dimensional YaleBrown Obsessive-Compulsive Scale; CGI = Clinical Global Impressions Severity of IIIness scale; $M I$ = Motivational Interviewing; $T M=$ Thought Mapping; $C B G T=$ Cognitive Behavioral Group Therapy; $O C D=$ Obsessive-Compulsive Disorder; $S D=S t a n d a r d$ Deviation; $\Delta_{\text {mean }}=($ post treatment value - pre treatment value) / pre treatment value); $n=$ sample size; $t_{s}=$ Student's $t$ test; $U_{M W}=$ Mann-Whitney's $U$ test.

\section{Results}

\section{Baseline data}

The sample included 13 (65\%) women in the MI+TM+CBGT and $15(75 \%)$ women in the control group, aged 18-65 years. Seventeen of the patients were married, the largest group (42.5\%). Fifteen $(37.5 \%)$ participants were single, seven $(17.5 \%)$ were divorced and one $(2.5 \%)$ was widowed. There was no significant difference in the distribution of male and female patients across the groups $(\mathrm{p}=0.730)$ or significant difference in the marital status ( $\mathrm{p}=0.225)$ of the two groups. Twenty-eight patients $(70 \%)$ met criteria for comorbid psychiatric disorders, including major depressive disorder $(\mathrm{n}=16 ; 40 \%)$, social phobia $(\mathrm{n}=12 ; 30 \%)$, simple phobia $(\mathrm{n}=10 ; 25 \%)$, compulsive buying $(\mathrm{n}=5 ; 12.5 \%)$, skin picking $(\mathrm{n}=5 ; 12.5 \%)$ and posttraumatic stress disorder $(\mathrm{n}=3 ; 7.5 \%)$. No evidence of mismatch was observed at baseline between the MI+TM+CBGT and the control group for demographic and clinical characteristics. The main demographic and clinical characteristics of the sample are described in Table 2.

When OCD symptom dimensions were examined using the DY-BOCS, 34 (85\%) patients reported symmetry, order and arrangement symptoms; 29 (72.5\%) miscellaneous symptoms; 24 (60.5\%) had aggression symptoms; 23 (57.5\%) contamination, cleaning and washing symptoms; 23 (57.5\%) hoarding symptoms, and seven $(12.5 \%)$ sexual-religious symptoms. There were no statistically significant differences between the MI+TM+CBGT group and the control group for mean DY-BOCS total score at baseline $(\mathrm{t}=-1.50, \mathrm{df}=38, \mathrm{p}=0.142)$ or when each dimension was considered separately: aggression dimension $\left(X^{2}=0.100\right.$, $\mathrm{df}=1, \mathrm{p}=0.747) ;$ sexual/religious dimension $\left(\mathrm{X}^{2}=0.173, \mathrm{df}=1\right.$, $\mathrm{p}=0.677)$; symmetry dimension $\left(\mathrm{X}^{2}=0.000, \mathrm{df}=1, \mathrm{p}=1.000\right)$; contamination dimension $\left(\mathrm{X}^{2}=0.102, \mathrm{df}=1, \mathrm{p}=0.749\right)$; hoarding dimension $\left(X^{2}=0.102, \mathrm{df}=1, \mathrm{p}=0.749\right)$ and the miscellaneous dimension $\left(X^{2}=3.135, \mathrm{df}=1, \mathrm{p}=0.077\right)$.

Mean Y-BOCS baseline scores $(\mathrm{t}=-1.02, \mathrm{df}=38, \mathrm{p}=0.313)$, Y-BOCS Obsessions subscale $(\mathrm{t}=-1.12, \mathrm{df}=38, \mathrm{p}=0.271)$ and Y-BOCS Compulsions subscale $(\mathrm{t}=-0.16, \mathrm{df}=38, \mathrm{p}=0.871)$ for the MI+TM+CBGT group and the control group were similar, and did not differ for those receiving concurrent anti-obsessive medication relative to those who were not $(\mathrm{p}=0.442)$.

\section{Treatment response}

Results of pre/post-treatment outcome measures for the $\mathrm{MI}+\mathrm{TM}+\mathrm{CBGT}$ and the control groups are presented in Table 3.

The comparison of mean rate of improvement, accessed by the average of the $\Delta$ mean of all outcome variables between

Table 2 - Demographic and clinical characteristics of participant conditions

\begin{tabular}{lccc}
\hline \multicolumn{1}{c}{ Variable } & MI+TM CBGT group (n= 20) & Control group (n = 20) & p \\
\hline Age (years) & $36.5(10.7)$ & $36.6(12.4)$ & 0.968 \\
Age at onset of OCD (years) & $9.75(3.21)$ & $10.5(4.2)$ & 0.505 \\
Mean duration of illness (years) & $25.5(10.5)$ & $23.9(13.8)$ & 0.769 \\
Mean age at which OCD symptoms started to & $27.6(12.8)$ & $28.3(13.6)$ & 0.859 \\
interfere with daily activities (years) & & & \\
Education (years) & $15.4(3.26)$ & $14.1(3.37)$ & 0.206 \\
Stable use of anti-obsessional drugs [n (\%)] & $6(30)$ & $7(35)$ & 0.744 \\
\hline
\end{tabular}

$M I=$ Motivational Interviewing; $T M=$ Thought Mapping; $C B G T=$ Cognitive Behavioral Group Therapy

Except where otherwise indicated, results are expressed as mean (SD). 
MI+TM+CBGT group and control group at the end of the treatment are presented in Table 1.

\section{Discussion}

The present study examined which obsessive compulsive symptom dimensions could be changed by adding two individual sessions of MI+TM before CBGT. Participants in both the MI+TM and control conditions received the CBGT. The treatments differed in the type of individual sessions received prior to CBGT. Usually, OCD patients believe that using rituals can be a helpful strategy to manage the anxiety that arises from feared situations. MI+TM was used to inform patients that the most effective way to reduce their fear is to confront the feared situations in which they experienced obsessions, without performing any rituals, and to wait for the reduction of anxiety. MI+TM might help patients to explore and resolve their ambivalence about whether or not to utilize rituals. MI+TM explicitly address motivation to change before CBGT, and assist the patient in how to make the best use of CBGT. TM ensures that patients receive an individualized case formulation and that the rationale for the ERP is thoroughly understood. In contrast, the control group did not explicitly focus on enhancing commitment to change at the outset. Therefore we conclude that since the MI+TM treatment encourages patients to change it resulted in better outcomes.

At baseline, symmetry, order and arrangement were the most prevalent symptom dimension in both groups, and were phenomenologically similar to previous trials. ${ }^{2,6,27,28}$ In a recent article, Leckman et al. reported that CBT is mostly indicated for patients with symmetry/ordering, contamination/washing, and aggressive/checking symptoms. ${ }^{29}$ Studies from Mataix-Cols et al. suggest that the presence of symmetry/ordering symptoms predicted better response in refractory cases. ${ }^{30}$

CBGT was effective for most symptom dimensions of OCD. Both groups have been shown to be effective in reducing the DYBOCS global score and five of the dimension scores. Therefore
CBGT might be indicated for patients with contamination, aggressive, symmetry, hoarding and miscellaneous symptoms. Nevertheless, the rate of reduction in the DY-BOCS global score and each dimension score (except the sexual/religious dimension) were significantly higher in patients treated with MI+TM+CBGT.

As shown in Table 1, at the end of the treatment, the group $\mathrm{MI}+\mathrm{TM}+\mathrm{CBGT}$ showed significant improvement in the dimensions of aggression and contamination, compared to CBGT alone. Hoarding showed a statistical trend towards improvement. Similarly, the DY-BOCS total score showed a statistical trend towards improvement. The CGI for the MI+TM+CBGT group showed a mean rate of improvement with a statistical trend. As Miller described, motivational interviewing can synergistically amplify the effect of other treatments. ${ }^{31}$ The combined effects of individualized treatment with elements of MI and TM obviously have had a large synergetic effect on the group intervention. These modifications suggest that changes in the dimensions were not just associated with global improvement of OCD, but could be associated with the addition of MI+TM to CBGT. One possibility would be that MI+TM helps patients to "think through" the pros (or benefits) and cons (or costs) of a particular belief or behavior in order to learn more about what they would identify as an important issue. After reflecting they can identify their own individual problem-solving strategies.

Clinical implications of this study indicate that special attention should be paid to patients with the dimension of sexual/religious symptoms. At pre- to post-treatment, there were no significant differences in the scores for the sexual/religious symptom dimension for patients treated with MI+TM+CBGT and for those in the control condition, which supports previous studies. ${ }^{4,32}$ Our findings suggest that patients with sexual/religious symptoms may have more difficulty with CBGT than other OCD patients. One possible explanation for our findings is that patients with sexual/ religious symptoms may have more difficulty recognizing the irrational nature of their symptoms than other patients, and as a result, these symptoms are more difficult to challenge. Fullana

Table 3 - Mean (SD) scores for a sample of 40 OCD outpatients in all outcome variables at baseline and post-treatment

\begin{tabular}{|c|c|c|c|c|}
\hline & \multicolumn{2}{|c|}{$M I+T M+C B G T(n=20)$} & \multicolumn{2}{|c|}{ Control group $(n=20)$} \\
\hline & pre & post & pre & post \\
\hline DY-BOCS global score & $22.6(2.6)$ & $6.8(4.4)^{\star *}$ & $24.1(3.5)$ & $11.8(8.3)^{\star *}$ \\
\hline Aggression & $5.9(5.0)$ & $1.5(2.6)^{*}$ & $5.5(5.4)$ & $2.7(3.4)^{* *}$ \\
\hline Sexual/religious & $1.3(3.4)$ & $0.8(2.7)$ & $1.6(4.2)$ & $0.9(3.1)$ \\
\hline Symmetry & $8.4(4.7)$ & $1.9(2.7)^{\star \star}$ & $8.9(4.5)$ & $3.7(4.3)^{\star \star}$ \\
\hline Contamination & $5.4(5.3)$ & $0.6(1.4)^{* *}$ & $6.5(5.7)$ & $2.4(3.3)^{* *}$ \\
\hline Hoarding & $4.2(4.5)$ & $0.6(1.3)^{\star *}$ & $3.8(3.6)$ & $1.7(2.9)^{*}$ \\
\hline Miscellaneous & $5.6(4.2)$ & $1.1(1.7)^{\star \star}$ & $6.0(5.8)$ & $1.9(3.8)^{\star \star}$ \\
\hline Y-BOCS total score & $29.4(3.7)$ & $7.1(4.1)^{\star \star}$ & $30.5(3.4)$ & $12.2(10.4)^{\star \star}$ \\
\hline Y-BOCS obsession & $13.9(2.4)$ & $4.1(2.3)^{\star *}$ & $14.6(1.8)$ & $5.8(5.1)^{\star *}$ \\
\hline Y-BOCS compulsion & $15.6(2.0)$ & $2.9(2.7)^{\star *}$ & $15.9(1.9)$ & $6.3(5.5)^{* *}$ \\
\hline CGI & $5.1(0.5)$ & $1.1(0.5)^{\star *}$ & $5.30(0.5)$ & $1.9(1.5)^{\star *}$ \\
\hline
\end{tabular}

Paired t-test or Wilcoxon test were used when appropriate; YBOCS = Yale-Brown Obsessive-Compulsive Scale; DY-BOCS= Dimensional YaleBrown Obsessive-Compulsive Scale; CGI = Clinical Global Impressions Severity of Illness scale; MI = Motivational Interviewing; TM = Thought Mapping; CBGT= Cognitive Behavioral Group Therapy; $O C D=$ Obsessive-Compulsive Disorder; SD = Standard Deviation; Pre = pre-treatment; Post $=$ post- treatment.

$* p<0.05$

${ }^{* *} p<0.01$ 
et al. ${ }^{3}$ and Mataix-Cols et al. ${ }^{4}$ point out that sexual or religious obsessions have been strongly associated with poor treatment response in previous studies and might be less likely to respond to serotonin reuptake inhibitors (SRIs) and behavior therapy. Therefore, more specific treatment strategies tailored for the sexual/religious symptom dimension are probably necessary. Other studies, ${ }^{33,34}$ however, did not confirm these findings.

In this study, patients with hoarding symptoms tended to improve more with MI+TM+CBGT as compared with those in the control group. It could be speculated that MI+TM might bring additional benefits to CBGT. Our results are in line with other studies that suggest that hoarders can be more successfully treated with a multifaceted cognitive-behavioural intervention than with regular CBT. ${ }^{32}$

There were no significant differences in the Y-BOCS total scores, but we observed a statistical tendency for improvement in the MI+TM+CBGT group compared to CBGT alone. Interestingly, the Y-BOCS compulsion score was significantly improved in the MI+TM+CBGT group compared to CBGT alone. It is important to point out that the improvement in compulsion is an extremely relevant result for this study. A possible explanation may be that the addition of MI+TM to CBGT may exert most of its impact on those dimensions which have a more "compulsive" component. This is in agreement with the finding that the dimensions which improved most were contamination (i.e., hand washing, avoidance) and aggression (i.e., checking in order to prevent unwanted outcomes or to make sure one did not harm anybody). One of the goals of the MI+TM individual sessions was to encourage the patients, prior to the CBGT, to face the expected increase in anxiety experienced during the OCD prevention exercises (ERP). Moreover, the individual sessions were also used to give the patients in the MI+TM+CBGT group explanations about how avoiding the use of rituals will gradually diminish the frequency of obsessions as well as the suffering elicited by them. Thus, the improvement in compulsion suggests that the intervention, i.e. MI+TM session, accomplished its objective, which was to focus on ameliorating the compulsions.

Although these results seem promising, important limitations of the present study must be considered. Firstly, a selection bias could account for the exceptionally large treatment effect size obtained in this study. Specifically, differently from other clinical studies, patients that presented several comorbidities were excluded from the sample. The severity of the comorbidities that were in fact present, such as depression and social phobia, was mild. In addition, the screening process involved selecting patients who were particularly motivated to participate in group therapy. The selection of highly motivated patients is evident since the dropout rate was considerably smaller than other similar studies have previously reported. Thus, the selection bias and the small sample size, which render our findings susceptible of statistical errors, limit the use of our results to extrapolate the outcome of using the treatment strategies employed in this study. However, even if our results may not represent the entire OCD patient population, this does not undermine the contribution of our findings to the field, given that it is the first time that MI+TM have been used before CBGT to compare the changes in obsessive-compulsive symptoms according to six different dimensions in the treatment of OCD. Future studies using different exclusion criteria, screening processes and larger sample sizes may show different results. The use of MI and TM may be effective in treating a different sample although the size of the treatment effect may not be as large as the one obtained in this study. The strength of this study is its randomized clinical trial design. Future research is needed to expand the present findings: for instance, how the elements specific to the MI-TM intervention might have influenced the response to CBGT and which components of MI-TM are most prominent. The lack of discriminative measures of the MI and TM interventions makes it difficult to determine which of these interventions is/are responsible for the results. Secondly, assessments did not include instruments to measure possible confounding factors such as motivation to change, fear, adherence to treatment or homework compliance. As a result, the outcomes may not generalize to the OCD adult outpatients as a whole. It is important to note that, although the stages of change have not been systematically assessed, the way a patient responds to interventionist feedback in relation to problem behavior offers strong evidence about the patient's motivation and readiness to change that behavior. ${ }^{31}$ Thirdly, we recognize the limitations that arise from the DY-BOCS not yet having a cut-off point for the global score and each dimension since it could lead to the inclusion of subclinical symptoms in some dimensions. However, in this study, we aimed to investigate whether adding two individual sessions of MI+TM to CBGT, which is a completely novel approach that has not been employed in the treatment of OCD, would influence the outcome of the treatment by affecting the scores of several dimensions of $\mathrm{OCD}$ symptoms compared to CBGT alone. Finally, the absence of long-term follow-up data limits our findings. Future studies are needed to evaluate the stability of the therapeutic benefits over time. Despite these limitations, this is the first randomized study which uses MI+TM before CBGT to compare the changes in OC symptom dimensions and it represents an important contribution to our knowledge regarding the treatment of OCD.

To conclude, this study used a Motivational Interviewing and Thought Mapping approach which is not routinely employed in OCD treatment programs. The results indicate beneficial effects of adding MI+TM to CBGT for OCD adult outpatients.

\section{Acknowledgements}

We would like to thank the Hospital de Clínicas of the Federal University of Rio Grande do Sul (HCPA-UFRGS) which has made this study possible. We would like to thank Andreia Raffin, Cenita Borges and Lucas Lovato for their assistance with treatment. We also would like to thank Kátia Niederauer, Vinícius Dornelles and Ygor Londero for their assistance with assessment interviews. The authors thank Dr. Manuela Polydoro for her review of the preliminary forms of this manuscript. Finally, we would like to thank Brian Rush for his s upport on research design and 
scientific matters and Ceres Oliveira for her statistical advice. Dr. Elisabeth Meyer has a doctoral grant from Conselho Nacional de Desenvolvimento Científico e Tecnológico (CNPQ), process number 142030/2006-6. Dr. Roseli G. Shavitt has a post-doctoral grant from Fundação de Amparo à Pesquisa do Estado de São Paulo (FAPESP), process number 06/61459-7.

\section{Disclosures}

\begin{tabular}{|c|c|c|c|c|c|c|c|}
\hline $\begin{array}{l}\text { Writting } \\
\text { group } \\
\text { member }\end{array}$ & Employment & Research grant $^{1}$ & $\begin{array}{l}\text { Other research grant or } \\
\text { medical continuous } \\
\text { education }\end{array}$ & $\begin{array}{l}\text { Speaker's } \\
\text { honoraria }\end{array}$ & $\begin{array}{l}\text { Ownership } \\
\text { interest }\end{array}$ & $\begin{array}{l}\text { Consultant/ } \\
\text { Advisory } \\
\text { board }\end{array}$ & Other $^{3}$ \\
\hline $\begin{array}{l}\text { Elisabeth } \\
\text { Meyer }\end{array}$ & HCPA & CNPQ & - & $\begin{array}{c}\text { Speeches } \\
\text { and courses* }\end{array}$ & - & - & - \\
\hline $\begin{array}{l}\text { Roseli G. } \\
\text { Shavitt }\end{array}$ & $\begin{array}{l}\text { Ipq-HC- } \\
\text { FMUSP }\end{array}$ & FAPESP & - & - & - & - & - \\
\hline $\begin{array}{l}\text { Carl } \\
\text { Leukefeld }\end{array}$ & $\begin{array}{l}\text { U.S. College of } \\
\text { Medicine, } \\
\text { University of } \\
\text { Kentucky }\end{array}$ & $\begin{array}{c}\text { U.S. National } \\
\text { Institutes } \\
\text { of Health } \\
\text { Purdue Pharma }\end{array}$ & - & $\begin{array}{l}\text { Speeches } \\
\text { and } \\
\text { consultation* }\end{array}$ & - & $\begin{array}{c}\text { U.S. } \\
\text { Universities* } \\
\text { U.S. National } \\
\text { Institutes of } \\
\text { Health* }\end{array}$ & - \\
\hline $\begin{array}{l}\text { Elizeth } \\
\text { Heldt }\end{array}$ & $\begin{array}{l}\text { UFRGS } \\
\text { HCPA }\end{array}$ & - & - & - & - & - & - \\
\hline $\begin{array}{l}\text { Fernanda } \\
\text { P. Souza }\end{array}$ & HCPA & - & - & - & - & - & - \\
\hline $\begin{array}{l}\text { Paulo } \\
\text { Knapp }\end{array}$ & HCPA & - & - & - & - & - & - \\
\hline $\begin{array}{l}\text { Aristides } \\
\text { V. Cordioli }\end{array}$ & $\begin{array}{c}\text { UFRGS } \\
\text { HCPA }\end{array}$ & - & - & $\begin{array}{l}\text { Speeches } \\
\text { and courses* }\end{array}$ & - & - & Copyright* \\
\hline \multicolumn{8}{|c|}{$\begin{array}{l}\text { *Modest } \\
\text { ** Significant } \\
\text { *** Significant. Amounts given to the author's institution or to a colleague for research in which the author has participation not directly to the author. } \\
\text { Note: IPq-HC-FMUSP = Departamento e Instituto de Psiquiatria do Hospital das Clínicas da Faculdade de Medicina da Universidade de São Paulo; } \\
\text { FAPESP = Fundação de Amparo à Pesquisa do Estado de São Paulo; HCPA = Hospital de Clínicas de Porto Alegre; CNPQ = Conselho Nacional de } \\
\text { Desenvolvimento Cientifico e Tecnológico; UFRGS = Universidade Federal do Rio Grande do Sul. }\end{array}$} \\
\hline
\end{tabular}

\section{References}

1. Mataix-Cols D, Fullana MA, Alonso P, Menchón JM, Vallejo J. Convergent and Discriminant Validity of the Yale-Brown Obsessive-Compulsive Scale Symptom Checklist. Psychother Psychosom. 2004;73(3):190-6.

2. Rosario-Campos MC, Miguel EC, Quatrano S, Chacon P, Ferrao Y, Findley D, Katsovich L, Scahill L, King RA, Woody SR, Tolin D, Hollander E, Kano Y, Leckman JF. The Dimensional Yale-Brown Obsessive-Compulsive Scale (DY-BOCS): an instrument for assessing obsessive-compulsive symptom dimensions. Mol Psychiatry. 2006;11(5):495-504.

3. Fullana MA, Tortella-Feliu M, Caseras X, Taberner J, Torrubia R, Mataix-Cols D. Temporal stability of obsessive-compulsive symptom dimensions in an undergraduate sample a prospective 2-year follow-up study. Behav Modif. 2007;31(6):815-24.

4. Mataix-Cols D, Rauch SL, Baer L, Eisen JL, Shera DM, Goodman WK, Rasmussen SA, Jenike MA. Symptom stability in adult obsessivecompulsive disorder: Data from a naturalistic two-year follow-up study. Am J Psychiatry. 2002;159(2):263-8.

5. Stein DJ, Andersen EW, Overo KF. Response of symptom dimensions in obsessive-compulsive disorder to treatment with citalopram or placebo. Rev Bras Psiquiatr. 2007;29(4):303-7.

6. Sookman D, Abramowitz JS, Calamari JE, Franklin R, Wilhelm S, McKay D. Subtypes of obsessive-compulsive disorder: implications for specialized cognitive behavior therapy. Behav Ther. 2005;36(4):393-400.

7. Abramowitz J, McKay D, Taylor S. Special series subtypes of obsessivecompulsive disorder. Behav Ther. 2005;36(4):367-9.

8. Rosa-Alcázar AI, Sánchez-Meca J, Gómez-Conesa A, Marín-Martínez F. Psychological treatment of obsessive-compulsive disorder: A metaanalysis. Clin Psychol Rev. 2008;28(8):1310-25.
9. Hofmann SG, Smits JA. Cognitive-behavioral therapy for adult anxiety disorders: a meta-analysis of randomized placebo-controlled trials. J Clin Psychiat. 2008;69(4):621-32.

10. Miller WR. Re-discovering fire: small interventions, large effects. Psychol Addict Behav. 2000;14(1):6-18.

11. Miller W, Rollnick S. Motivational interviewing: preparing people for change. 2nd ed. New York: The Guilford Press; 2002.

12. Rollnick S, Miller WR, Butler CC. Motivational interviewing in health care: helping patients change behavior. New York: The Guilford Press; 2008.

13. Leukefeld CG, Pechansky F, Martin SS, Surratt HL, Inciardi JA, Kessler FHP, Orsi, MM, Von Diemen L, Meyer Da Silva E. Tailoring an HIVprevention intervention for cocaine injectors and crack users in Porto Alegre, Brazil. AIDS Care. 2005;17(1):77-87.

14. Inciardi JA, Surratt HL, Pechansky F, Kessler F, Von Dimen L, Meyer da Silva E, Martin SS. Changing patterns of cocaine use and HIV risks in the South of Brazil. J Psychoactive Drugs. 2006;38(3):305-10.

15. Prochaska JO, DiClemente CC. Toward a comprehensive model of change. In: Miller W, Heather N, editors. Treating addiction behaviors. New York: Plenum Press; 1986. p.3-27.

16. Leukefeld C, Brown C, Clark J, Godlaski T, Hays R. Behavioral therapy for rural substance abusers. Lexington, KY: University of Kentucky Press; 2000.

17. Tavares M. Entrevista clínica estruturada para diagnóstico dos transtornos do eixo $I$ do DSM-IV - Edição do paciente, versão 2.0 (SCID-I/P, Versão 2.0). Tradução brasileira. Brasília, DF: Instituto de Psicologia da Universidade de Brasília; 1996.

18. First MB, Spitzer RL, Gibbon M, Williams JB. Structured clinical interview for DSM-IV axis I disorders - clinician version (SCID-CV). Washington (-DC): American Psychiatric Press; 1997. 
19. Cordioli AV, Heldt E, Bochi DB, Margis R, Sousa MB, Tonello JF, Manfro GG, Kapczinski F. Cognitive-behavioral group therapy in obsessivecompulsive disorder: a randomized clinical trial. Psychother Psychosom. 2003;72(4):211-6.

20. Braga D, Cordioli AV, Manfro GG. Cognitive-behavioral group therapy for obsessive-compulsive disorder: a 1 year follow-up. Acta Psychiatr Scand. 2005;112(3): 180-6.

21. Sousa MB, Isolan LR, Oliveira RR, Manfro GG, Cordioli AV. A Randomized Clinical Trial on Cognitive-Behavioral Group Therapy and Sertraline in the Treatment of Obsessive-Compulsive Disorder. J Clin Psych. 2006;67(7):1133-9.

22. Cordioli AV, Heldt E, Bochi DB, Margis R, Sousa MB, Juliano F, Tonello JF, Teruchkin B, Kapczinski F. Cognitive-behavioral group therapy in obsessive-compulsive disorder: a clinical trial. Rev Bras Psiquiatr. 2002;24(3):113-20.

23. Westra HA, Dozois DJ. Preparing clients for cognitive behavioral therapy: a randomized pilot study of motivational interviewing for anxiety. Cogn Ther Res. 2006;30(4):481-98.

24. Asbahr FR, Lotufo Neto F, Turecki GX, Del Porto JÁ, Rodríguez LR, Baruzzi M, Lima MA, Gentil V. Escala yale-brown de sintomas obsessivocompulsivos. Tradução brasileira. São Paulo; 1992.

25. Goodman WK, Price LH, Ramussen SA, Mazure C, Fleischmann RL, Hill CL, Heninger GR, Charney DS. The Yale-Brown ObsessiveCompulsive Scale: I Development, use and reliability. Arch Gen Psychiatry. 1989;46(11):1006-11.

26. Guy W. Clinical Global Impression (CGI). In: ECDEU Assessment Manual for Psychopharmacology. US Department of Health and Human Services, Public Health Service, Alcohol Drug Abuse and Mental Health Administration, NIMH psychopharmacology Research branch. Rockville, MD: National Institute of Mental Health; 1976.

27. Ferrão YA, Shavitt RG, Bedin NR, de Mathis ME, Lopes AC, Fontenelle LF, Torres AR, Miguel EC. Clinical features associated to refractory obsessive-compulsive disorder. J Affect Disord. 2006;94(1-3):199-209.

28. Miguel EC, Ferrão YA, Rosario M, de Mathis ME, Torres AR, Fontenelle LF, Hounie A, Shavitt RG, Cordioli AV, Gonzáles CH, Petribú K, Diniz JB, Malavazzi DM, Torresan RC, Raffin AL, Meyer E, Braga DT, Borcato S, Valério C, Gropo LN, Prado HS, Perin EA, Santos SI, Copque H, Borges MC, Lopes AP, da Silva ED. Brazilian Research Consortium on Obsessive-Compulsive Spectrum Disorders. The Brazilian Research Consortium on Obsessive-Compulsive Spectrum Disorders: recruitment, assessment instruments, methods for the development of multicenter collaborative studies and preliminary results. Rev Bras Psiquiatr. 2008;30(3):185-96.

29. Leckman JF, Rauch SL, Mataix-Cols D. Symptom Dimensions in ObsessiveCompulsive Disorder: Implications for the DSM-V. CNS Spectr. 2007;12(5):376-87.

30. Mataix-Cols D, Rosario-Campos MC, Leckman JF. A multidimensional model of obsessive-compulsive disorder. Am J Psychiatry. 2005;162(11):228-38.

31. Miller, WR. When is it motivational interviewing? Addiction. 2001;96(12): 1770-2.

32. Mataix-Cols D, Marks IM, Greist JH, Kobak KA, Baer L. Obsessive-compulsive symptom dimensions as predictors of compliance with and response to behaviour therapy: results from a controlled trial. Psychother Psychosom. 2002;71(5):255-62.

33. Abramowitz JS, Franklin ME, Schwartz SA, Furr JM. Symptom presentation and outcome of cognitive-behavior therapy for obsessive-compulsive disorder. J Consult Clin Psych. 2003;71(6):1049-57.

34. Freeston MH, Ladouceur R, Gagnon F, Thibodeau N, Rheaume J, Letarte $\mathrm{H}$, Bujold A. Cognitive-behavioral treatment of obsessive thoughts: a controlled study. J Consult Clin Psych. 1997;65(3):405-13. 